\title{
Investigation of structural phase transitions and superionic property of a Vanthoffite mineral, $\mathrm{Na}_{6} \mathrm{Co}\left(\mathrm{SO}_{4}\right)_{4}$
}

\author{
Ajana Dutta, Diptikanta Swain, T. N. Guru Row \\ Solid State and Structural chemistry unit, Indian Institute of Science, Bangalore, India \\ ajanadutta1@gmail.com
}

There are several naturally occurring minerals that show temperature induced phase transitions, leading to a variety of materials which display specific properties such as superionic conductivity and ferroic behaviour. ${ }^{[1-5]}$ Some of the minerals crystallize with different hydration levels and show phase transitions at elevated temperature. ${ }^{[2,3]}$ It is important to note that superionic conductors exhibit high ionic conductivity $\left(\approx 10^{-3}\right.$ to $\left.10^{-1} \mathrm{~S} / \mathrm{cm}\right)$ at modest temperatures $\left(400-600{ }^{\circ} \mathrm{C}\right)$ and are playing a major role to design next generation solid state batteries. ${ }^{[1,4]}$ The ionic conductivity of a material and its crystal structure are highly correlated with each other. In this context, the phase behaviour of compound belongs to the Vanthoffite family, $\mathrm{Na}_{6} \mathrm{Co}\left(\mathrm{SO}_{4}\right)_{4} \cdot \mathrm{xH}_{2} \mathrm{O}(\mathrm{x}=2,4)$ with temperature has been investigated. Single crystals of di-and tetra-hydrates of the mineral $\mathrm{Na}_{6} \mathrm{Co}\left(\mathrm{SO}_{4}\right)_{4}$ grow concomitantly from aqueous solution containing stoichiometric molar ratio of starting materials. Both of this hydrated forms have similar morphology and crystallize in $P \overline{1}$ with $Z=1$. In fact, the elusive anhydrous crystal $\left(\mathrm{Na}_{6} \mathrm{Co}\left(\mathrm{SO}_{4}\right)_{4}\right)$ [inset Fig. 1a] could be produced in situ from the tetra-hydrate/dihydrate crystal and the transition pathway has been characterized via variable temperature single crystal X-ray diffraction analysis. Further, we have also examined the phase transitions displayed by the anhydrous phase using in situ powder X-ray diffraction and in situ Raman spectroscopy with respect to temperature [Fig. 1b]. The structural features are shown to correlate with the conductivity measurements with the super ionic behaviour $\left(\sigma=1.1 \times 10^{-2} \mathrm{~S} / \mathrm{cm}\right)$ appearing at $570{ }^{\circ} \mathrm{C}$ [Fig. 1a]. These observations are significant for the development and understanding of mineral based solid electrolytes.
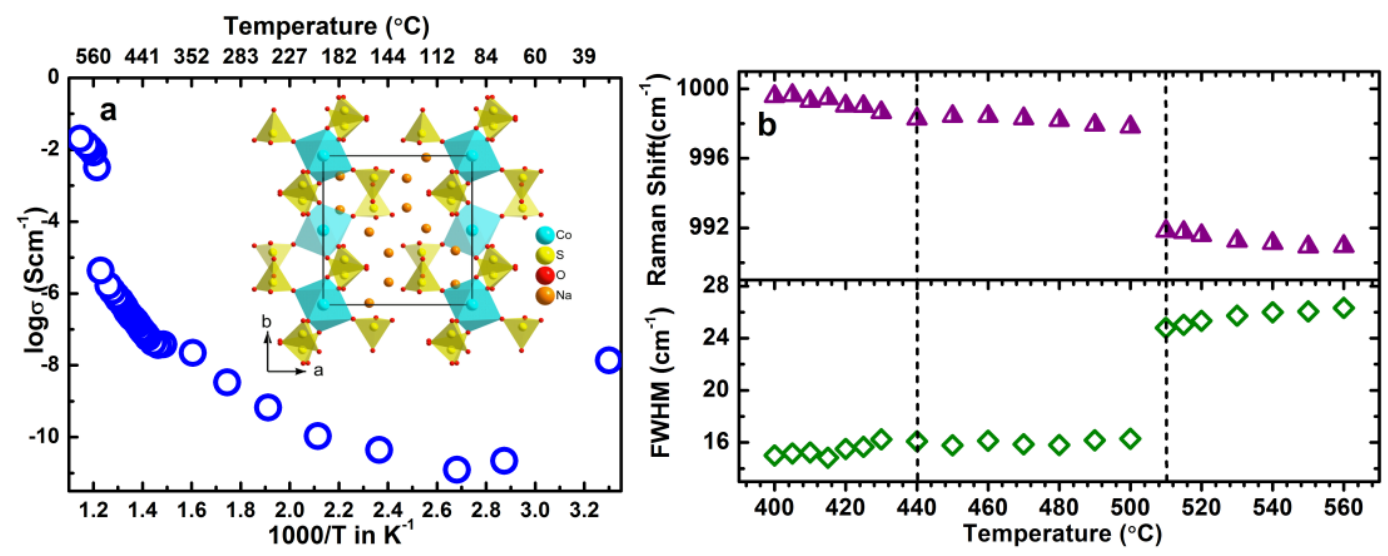

Figure 1 (a) Temperature dependent Conductivity plot of $\mathrm{Na}_{6} \mathrm{Co}\left(\mathrm{SO}_{4}\right)_{4}$, the inset shows crystal structure of $\mathrm{Na}_{6} \mathrm{Co}\left(\mathrm{SO}_{4}\right)=$ and, (b) Temperature evolution of Raman shift and FWHM of symmetric stretching mode of the SO4 ion

[1] Sharma, V., Swain, D., Guru Row, T. N. (2017). Inorg. Chem. 56, 6048.

[2] Swain, D., Guru Row, T. N. (2009). Inorg. Chem. 48, 7048.

[3] Saha, D., Madras, G., Guru Row, T. N. (2011). Cryst.Growth Des. 11, 3213.

[4] Swain, D., Guru Row, T. N. (2007). Chem. Mater. 19, 347.

[5] Pradhan, G. K., Swain, D., Guru Row, T. N., Narayana, C. (2009). J. Phys. Chem. A 113, 1505.

Keywords: Minerals; Superionic; Phase transitions; Raman analysis; PXRD 